\title{
Estabilidade e Mudanças nas Práticas Educativas de Mães e Pais dos 18 para os 24 Meses de Vida da Criança ${ }^{1}$
}

\author{
Patrícia Alvarenga \\ Universidade Federal da Bahia \\ Cesar Augusto Piccinini \\ Giana Bitencourt Frizzo \\ Rita Sobreira Lopes \\ Universidade Federal do Rio Grande do Sul \\ Jonathan Tudge \\ University of North Carolina at Greensboro (EUA)
}

\begin{abstract}
RESUMO
O presente estudo investigou a estabilidade e as mudanças nas práticas educativas de mães e pais entre os 18 e os 24 meses de seus filhos. Além disso, foram comparadas as práticas educativas maternas e paternas aos 24 meses. Participaram do estudo 18 famílias. As mães e os pais responderam separadamente uma entrevista estruturada sobre práticas educativas parentais envolvendo seis situações de conflito do dia a dia da criança. Os resultados indicaram um aumento significativo no relato de práticas indutivas maternas dos 18 para os 24 meses. Aos 24 meses, diferenças significativas entre mães e pais foram encontradas em algumas das práticas indutivas ("explica" e "organiza ambiente") e no total de práticas coercitivas, com maior frequência de relatos maternos do que paternos. Discute-se o maior envolvimento das mães nos cuidados com as crianças e o impacto das mudanças no comportamento infantil características deste período do desenvolvimento sobre as práticas educativas maternas.
\end{abstract}

Palavras-chave: práticas educativas parentais; parentalidade; família; desenvolvimento social.

\section{ABSTRACT}

Stability and Change in Mothers' and Fathers' Child-rearing Practices from the $18^{\text {th }}$ to the $24^{\text {th }}$ Month

The present study investigated stability and changes in mothers' and fathers' child-rearing practices from their children's $18^{\text {th }}$ to $24^{\text {th }}$ month. In addition, maternal and paternal child-rearing practices were compared at 24 months. Eighteen families took part in the study. Mothers and fathers completed, individually, a structured interview on child-rearing practices involving six everyday conflict situations. The results indicated a significant increase in maternal report of inductive practices from 18 to 24 months. At 24 months, we found significant differences between mothers and fathers in some inductive practices ("explains" and "organizes environment") and in the total number of coercive practices. Mothers reported more child-rearing practices, overall, than did fathers. Mothers' greater involvement in child care and the impact of changes in children's behavior during this developmental period on child-rearing are discussed.

Keywords: child-rearing practices; parenthood; family; social development.

Ao longo do segundo ano de vida, a criança começa a passar por mudanças marcantes no que se refere às suas habilidades para interagir socialmente. Com a aquisição e ampliação do repertório verbal, ela vai se tornando progressivamente mais capaz de expressar seus desejos e pontos de vista, de negar-se a cooperar ou aceitar as demandas do ambiente e de negociar as exigências e solicitações dos pais, de outros adultos e dos pares. Estas aquisições podem ser compreendidas como um conjunto de habilidades sociais específicas que começam a se desenvolver, dentre as quais se destaca a assertividade. A assertividade permitirá à criança negociar sua independência no contexto das expectativas e exigências do mundo social. É em torno 
dos dois anos de idade que a criança começa a desenvolver o comportamento assertivo e uma das aquisições mais importantes para o desenvolvimento desta habilidade é a capacidade de dizer "não". Kuczynski, Kochanska, Radke-Yarrow e Girnius-Brown (1987) constataram que crianças que diziam "não" com maior frequência também se engajavam em mais negociações com suas mães. À medida que a criança começa a demonstrar assertividade, as práticas educativas parentais devem acomodar-se a essa nova aquisição no repertório infantil. Diante de um comportamento assertivo da criança, como a recusa em atender alguma ordem ou pedido (por exemplo, dizendo "não", "não quero" ou mesmo balançando a cabeça negativamente), as atitudes e práticas educativas parentais tendem a se alterar. Por exemplo, a mãe poderá explicar à criança porque ela deve cooperar, tentar persuadi-la tornando a tarefa atrativa, ou ainda abandonar seu objetivo em favor de alguma alternativa que a criança pareça aceitar melhor (Crockenberg \& Litman, 1990).

Ser capaz de recusar-se a fazer algo, ou saber dizer "não" são exemplos de comportamentos assertivos com importantes funções, que surgem nos primeiros anos da infância (Kuczynski \& cols., 1987). Quando os pais ou cuidadores da criança entendem esses comportamentos como uma busca saudável e normal de autonomia, ajudam-na a adquirir autocontrole, contribuem para o seu senso de competência e evitam conflitos desnecessários (Minuchin, 1982; Papalia \& Olds, 2000).

De qualquer modo, a qualidade desses ajustes no comportamento dos pais dependerá, entre outros aspectos, do repertório de práticas educativas parentais disponível. As práticas educativas parentais são estratégias de regulação do comportamento infantil, utilizadas pelos pais no processo de socialização dos filhos. Essas práticas destinam-se a direcionar o comportamento dos filhos no sentido de seguir certos princípios morais e adquirir habilidades que lhes garantam independência e autonomia, bem como capacidade para lidar com as demandas dos contextos sociais e o convívio em grupo. Por outro lado, tais estratégias também são utilizadas com o objetivo de suprimir ou reduzir comportamentos que sejam considerados socialmente inadequados ou desfavoráveis (Grusec \& Lytton, 1988; Hoffman, 1975, 1979, 1994; Mussen, Conger, Kagan \& Huston, 1990). Deste modo, é possível que pais e mães com bom repertório de habilidades parentais negociem, expliquem ou raciocinem com a criança, desde a mais tenra idade, sobre a situação que estão tentando resolver, enquanto pais com repertório escasso tendam a recorrer, com mais facilidade, a práticas coercitivas, como ameaças, castigos e palmadas.

Segundo Darling e Steinberg (1993), é importante que se investigue como as práticas educativas e os estilos parentais mudam ao longo do ciclo vital e também as vantagens e desvantagens de diferentes aspectos das práticas parentais em distintos períodos do desenvolvimento infantil. Para Dallaire e Weinraub (2005) estas questões, apontadas há mais de uma década, têm ainda recebido pouca atenção dos pesquisadores. Isto se torna especialmente importante, tendo em vista a existência de achados contraditórios. Por exemplo, alguns estudos indicam que as práticas educativas parentais tendem a alterar-se ao longo do desenvolvimento da criança (McNally, Eisenberg \& Harris, 1991; Roberts, Block \& Block, 1984). O uso de punição física, por exemplo, diminuiria à medida que a criança cresce. Além disso, à medida que a criança vai adquirindo domínio sobre a linguagem, os pais podem fazer mais uso de orientações verbais e explicações racionais (Mussen, Conger, Kagan \& Huston, 1990). A atribuição de maior ou menor competência e responsabilidade à criança por parte da mãe, também parece mediar as variações nas estratégias disciplinares utilizadas. Nesse sentido, mães que atribuem à criança maior responsabilidade e capacidade de compreensão da situação, tenderiam a interferir mais, utilizando inclusive com maior frequência, práticas coercitivas (Dix, Ruble \& Zambarano, 1989).

Por outro lado, há estudos que destacam a estabilidade dos comportamentos e estilos parentais. Segundo Darling e Steinberg (1993) apesar de os termos práticas educativas parentais (Hoffman, 1975, 1994) e estilos parentais (Baumrind, 1972) serem comumente empregados para referir-se ao mesmo aspecto da interação pais e filhos e do processo de socialização, eles enfatizam aspectos distintos, embora não incompatíveis. Como salientaram as autoras, o termo práticas educativas parentais refere-se mais precisamente às estratégias específicas empregadas pelos pais (ex.: punição física, explicação), enquanto que o termo estilos parentais designa as características globais ou gerais dos pais no que diz respeito a sua interação com os filhos (sensibilidade versus hostilidade, etc.). Nesse sentido, os estilos parentais poderiam ser considerados como uma espécie de contexto global que modula a influência de práticas educativas específicas.

Esta distinção é relevante para o exame dos estudos que indicam maior estabilidade nos estilos paren- 
tais, ao mesmo tempo em qe ioutros sugerem que as práticas específicas estariam mais sujeitas a mudanças. Dallaire e Weinraub (2005) chegaram a três achados importantes a respeito dessa questão investigando mães e pais nos primeiros seis anos de vida de seus filhos. Em primeiro lugar, as autoras encontraram que, embora a quantidade de sensibilidade e estimulação parental tenha variado ao longo dos anos, aqueles que nos primeiros anos de vida dos seus filhos eram mais sensíveis e estimuladores, mantiveram este padrão em etapas posteriores da investigação. Em segundo lugar, os aspectos negativos da parentalidade, como coerção e hostilidade, demonstraram menor estabilidade do que os fatores destacados acima. Em terceiro lugar, as autoras verificaram que os comportamentos parentais presentes nos primeiro anos da criança foram preditores robustos dos comportamentos parentais avaliados mais tarde, no sexto ano de vida. Com relação aos períodos do $15^{\circ}$ e do $24^{\circ}$ mês de vida da criança, Dallaire e Weinraub (2005) destacaram a estabilidade de alguns comportamentos parentais específicos como a sensibilidade e a presença apoiadora (prontidão e adequação das respostas maternas aos sinais de angústia e desconforto da criança), e também o desapego (não envolvimento e descaso em relação à necessidade da criança de atenção apropriada) e a atenção negativa (afeto negativo direcionado à criança). Nesta mesma perspectiva, o estudo de Landry, Smith, Swank, Assel e Vellet (2001) constatou a estabilidade relativa da sensibilidade e da responsividade parental nos quatro primeiros anos de vida.

Outra questão a ser considerada, diz respeito à distinção entre diferentes tipos de práticas educativas e o seu impacto sobre o desenvolvimento infantil. A relevância desta distinção é explicitada por Hoffman (1975, 1979, 1994), que as classificou em práticas indutivas e práticas coercitivas. As estratégias indutivas comunicam à criança a necessidade de mudança de comportamento, indicando as consequências do seu comportamento para si e para as outras pessoas. Isto propicia à criança a compreensão das implicações de suas ações e dos motivos que justificam a necessidade de mudança no seu comportamento, o que favorece o desenvolvimento de autonomia para utilizar esse tipo de informação na regulação do próprio comportamento, facilitando a internalização de padrões morais (Alvarenga \& Piccinini, 2001; Hart, Ladd \& Burleson, 1990; Hoffman, 1979;). Por outro lado, as estratégias de força coercitiva caracterizam-se pela aplicação direta da força, incluindo punição física, privação de privilégios e afeto, ou pelo uso de ameaças dessas atitudes. Tais práticas não favorecem a internalização de padrões morais porque condicionam o controle do comportamento da criança a intervenções externas e não à compreensão de suas implicações. Por esta razão, as práticas coercitivas estariam mais relacionadas a problemas de comportamento.

Alguns estudos brasileiros indicam uma tendência mais acentuada para a utilização de práticas indutivas com crianças em idade pré-escolar, na faixa etária de cinco a seis anos (Alvarenga \& Piccinini, 2003; Piccinini, Castro, Alvarenga, Vargas \& Oliveira, 2003). Contudo, o estudo de Alvarenga e Piccinini (2001), que avaliou as práticas educativas maternas em situações de conflito, encontrou uma frequência superior de práticas indutivas apenas entre as mães de crianças sem problemas de comportamento, enquanto que no grupo de crianças que apresentavam problemas de externalização (p. ex., agressividade e comportamento desafiador), predominaram as práticas coercitivas. Isso sugere que a associação entre práticas educativas e a idade da criança não é linear e depende de outras dimensões individuais relacionadas à criança e também ao contexto.

Uma questão investigada com menor frequência na literatura é a influência do gênero do genitor nas práticas educativas parentais. Piccinini, Frizzo, Alvarenga, Lopes e Tudge (2007), discutiram os achados de alguns estudos que indicam diferenças nos padrões de interação de pais e mães com seus filhos, bem como no seu envolvimento nos cuidados com a criança. Os achados sobre diferenças nos padrões de interação são controversos. Alguns estudos apontam para diferenças no comportamento de pais e mães, sugerindo que os pais utilizariam mais brinquedos e movimentos fortes, enquanto as mães seriam mais delicadas e utilizariam mais verbalizações (Parke, 1981; Schaffer, 1996). Outras pesquisas, como a de Belsky (1979), não encontraram diferenças entre pais e mães ao examinarem diferentes modalidades de interação. Contudo, os resultados acerca do envolvimento nos cuidados com a criança indicam uma tendência de envolvimento maior por parte das mães (Belsky, 1979; Booth, Spieker, Barnard \& Morisset, 1992), o que em nossa sociedade é o que também se sobressai.

Estudos sobre diferenças nas práticas educativas de pais e mães são escassos, particularmente no que se refere a crianças pequenas. $\mathrm{O}$ exame dos achados dessas investigações indica que diferenças tendem a aparecer, particularmente, em famílias de crianças que apresentam problemas de comportamento. Por exemplo, no estudo de Baker e Heller (1996), os pais 
demonstraram um estilo mais autoritário e menos indulgente e permissivo, bem como maior indiferença e menor envolvimento com os filhos quando comparados às mães. Por outro lado, no estudo de Bentley e Fox (1991), que comparou os estilos parentais de pais e mães de crianças de um a quatro anos, os achados indicaram não haver diferenças significativas entre as estratégias empregadas pelos pais e pelas mães. Nesta mesma perspectiva, o estudo de Chao e Kim (2000), que examinou os estilos parentais de 35 casais chineses residentes nos Estados Unidos, com crianças de 6 a 9 anos, também não constatou diferenças entre pais e mães.

Por fim, é importante destacar os resultados obtidos por Piccinini e cols. (2007) em estudo realizado com famílias que compõem a amostra do presente estudo, quando as crianças tinham 18 meses de vida. $\mathrm{O}$ estudo comparou as práticas educativas utilizadas por pais e mães em situações cotidianas com seus filhos. Os resultados revelaram um predomínio de práticas indutivas relatadas tanto pelas mães como pelos pais, seguidas de práticas coercitivas e de práticas de não interferência, e não indicaram diferenças significativas nas práticas educativas indutivas e coercitivas utilizadas por pais e mães naquela faixa etária.

Embora a literatura que examina as diferenças nas práticas educativas de pais e mães aponte para a ausência de diferenças, a questão da estabilidade das práticas ainda é uma lacuna importante presente na literatura. Enquanto alguns estudos indicam que as mudanças no comportamento infantil acarretam mudanças no repertório parental (Dix \& cols., 1989; McNally \& cols., 1991; Mussen \& cols., 1990; Roberts $\&$ cols., 1984), outros apontam para a estabilidade de alguns desses padrões (Dallaire \& Weinraub, 2005; Landry \& cols., 2001). Tais contradições podem ser explicadas, em parte, pela grande diversidade de conceitos e de medidas. Como já foi salientado, alguns estudos avaliam práticas ou comportamentos parentais, enquanto outros avaliam estilos ou atitudes parentais. Darling e Steinberg (1993) discutiram a relevância da distinção desses conceitos para a interpretação dos resultados das pesquisas. Enquanto variáveis que avaliam atitudes e estilos parentais apresentariam maior estabilidade, variáveis que se referem a comportamentos específicos, como as práticas educativas, investigadas no presente estudo, seriam mais suscetíveis a mudanças.

O presente estudo investigou a estabilidade e possíveis mudanças nas práticas educativas de pais e mães dos 18 para os 24 meses de vida das crianças.
Além disso, foram comparadas as práticas educativas maternas e paternas aos 24 meses. A hipótese inicial era de que aos 24 meses pais e mães relatariam mais práticas indutivas (ex. negociação e explicação) do que aos 18 meses, devido à crescente aquisição de autonomia e assertividade nas crianças, além do desenvolvimento da linguagem. Uma segunda hipótese foi de que não haveria diferenças nas práticas educativas maternas e paternas aos 24 meses da criança, a exemplo do que foi constatado no estudo anteriormente citado, que incluiu todas as famílias do presente estudo, comparando as práticas de pais e mães aos 18 meses de vida das crianças (Piccinini \& cols., 2007).

\section{MÉTODO}

\section{Participantes}

Participaram do estudo 18 famílias, em que o casal residia junto e que tivessem participado da coleta de dados tanto aos 18 como aos 24 meses de idade de seu filho ( 8 meninas e 10 meninos). As mães eram primíparas com idade média de 21 anos $(D p=4,43)$. A escolaridade média foi de 9 anos $(D p=2,25)$. Os pais tinham idade média de 24 anos $(D p=5,57)$ e escolaridade média de 9 anos $(D p=3,05)$. As famílias eram de diferentes níveis socioeconômicos (NSE), de acordo com critérios baseados em Hollingshead (1975) adaptados para o presente estudo por Tudge e Frizzo (2002). Das 18 famílias participantes, quatro (22\%) eram de NSE baixo, cinco (28\%) médio-baixo, sete $(39 \%)$ médio, um $(6 \%)$ médio-alto e um $(6 \%)$ de NSE alto.

A amostra foi selecionada do Estudo Longitudinal de Porto Alegre: da Gestação à Escola - ELPA (Piccinini \& cols., 2007; Piccinini, Lopes, Sperb \& Tudge, 1998), que acompanhou famílias, de diferentes configurações familiares e níveis socioeconômicos variados, da gestação até os dois primeiros anos na escola. Para o presente estudo foram selecionados todos os casais com único(a) filho(a) e que tinham dados completos dos pais e das mães nas duas fases de coleta. O estudo foi aprovado pelo Comitê de Ética da UFRGS (Resolução n 2006596).

\section{Delineamento, procedimentos e instrumentos}

Foi utilizado um delineamento longitudinal (Robson, 1995) a fim de verificar a estabilidade e possíveis mudanças nas práticas educativas maternas e paternas entre os 18 e os 24 meses das crianças. Além disso, se investigou eventuais diferenças nas práticas educativas maternas e paternas aos 24 meses de idade da criança. 
Como parte do ELPA, diversos instrumentos foram utilizados nas duas fases de coleta de dados (cf. Piccinini \& cols., 1998), mas destacam-se aqui apenas aqueles cujos dados foram utilizados no presente estudo, a saber: Entrevista de dados demográficos (GIDEP, 1998) que foi realizada na gestação, com o objetivo de investigar dados demográficos, tais como idade da mãe e do companheiro, escolaridade, profissão e estado civil; e a Entrevista sobre práticas educativas parentais (Piccinini \& cols., 2007), que foi realizada tanto aos dezoito quanto aos vinte e quatro meses da criança. Nessa entrevista foram apresentadas seis situações que normalmente ocorriam no cotidiano envolvendo conflitos, comportamentos inadequados ou desobediência da criança, a saber: a) a criança recusa-se a comer; b) a criança recusa-se a ficar com outra pessoa; c) a criança recusa-se a trocar de roupa; d) a criança recusa-se a dormir à noite; e) a criança recusa-se a entrar/sair do banho; e, f) a criança faz birra quando recebe um não. Após o relato de cada situação, eram investigadas as práticas educativas utilizadas pelas mães e pelos pais, até o máximo de três práticas relatadas por situação específica. As mães e os pais foram entrevistados separadamente e as entrevistas foram gravadas em audiotape e posteriormente transcritas para análise.

\section{RESULTADOS}

A análise de conteúdo (Bardin, 1977) foi utilizada para examinar as práticas educativas relatadas pelas mães e pelos pais nas diversas situações investigadas. Para fins de análise, foi utilizada a estrutura de categorias proposta por Alvarenga e Piccinini (2001), baseada em Hoffman $(1975,1979,1994)$, a qual já havia sido adaptada anteriormente para crianças de 18 meses de idade (Piccinini \& cols., 2007). Esta estrutura propõe a análise das práticas educativas parentais em três categorias: práticas educativas indutivas, práticas educativas coercitivas e não interferência, além de considerar uma categoria residual para as estratégias educativas que não puderam ser enquadradas nas categorias anteriores. Detalhes sobre as categorias utilizadas podem ser encontrados em Piccinini e cols. (2007).
Para fins de análise considerou-se até a terceira prática educativa relatada por cada mãe e cada pai. Como alguns participantes relataram o uso de apenas uma prática educativa, a fidedignidade foi calculada apenas sobre a primeira resposta relatada em cada uma das seis situações analisadas. $O$ índice de fidedignidade entre os codificadores na classificação das práticas, nas diversas categorias, foi calculado utilizando-se o coeficiente Kappa em uma amostra de $20 \%$ das entrevistas e atingiu o valor médio de 0,74 , o que é considerado bom (Robson, 1995). Após o estabelecimento do índice de fidedignidade, uma das autoras do presente estudo, com o auxílio de uma colega, classificaram separadamente todas as práticas educativas nas categorias e sub-categorias de análise. Por fim, eventuais discordâncias foram dirimidas por discussão e, apenas em duas situações, isto é, para o esclarecimento da categoria em que seriam classificadas duas unidades de análise, foi utilizado um terceiro juiz.

Para investigar a estabilidade e as mudanças nas práticas educativas mencionadas pelas mães e pelos pais aos 18 e 24 meses de vida da criança, utilizou-se o teste não-paramétrico Wilcoxon. Este teste estatístico foi adotado porque os dados não estavam distribuídos de acordo com a curva normal e por tratar-se de um delineamento dentre participantes (medidas repetidas). As Tabelas 1 e 2 apresentam a incidência média, o desvio padrão e o nível de significância das práticas educativas maternas e paternas, respectivamente, aos 18 e 24 meses de vida da criança.

Como pode ser visto, as análises revelaram um aumento significativo $(p<0,04)$ na frequência de práticas indutivas maternas dos 18 para os 24 meses de vida da criança. Entre as subcategorias, explica $(\mathrm{p}<0,06)$, aparece também como uma tendência ao aumento de frequência, embora a diferença não tenha sido significativa. Por outro lado, como pode ser visto na Tabela 2, as análises das estratégias paternas não revelaram nenhuma diferença significativa nos dois momentos investigados. 
TABELA 1

Média e Desvio-padrão das Práticas Educativas Maternas Relatadas aos 18 e 24 Meses de Idade da Criança $(n=18)$

\begin{tabular}{lccc}
\hline \multicolumn{4}{c}{ FAIXA ETÁRIA } \\
\hline Práticas educativas & 18 & 24 & $p$ \\
\hline Práticas Indutivas & $3,06(2,15)$ & $4,67(2,20)$ & 0,04 \\
Negocia e troca & $1,28(0,89)$ & $1,67(1,14)$ & 0,29 \\
Explica & $1,11(1,71)$ & $2,17(1,54)$ & 0,06 \\
Organiza ambiente & $0,33(0,59)$ & $0,56(0,51)$ & 0,36 \\
Comanda verbalmente sem coerção & $0,28(0,46)$ & $0,22(0,43)$ & 1,00 \\
\hline Práticas coercitivas & $2,94(1,80)$ & $3,44(1,69)$ & 0,16 \\
Pune verbalmente & $1,16(0,98)$ & $1,05(0,72)$ & 0,79 \\
Ameaça & $0,28(0,57)$ & $0,67(0,77)$ & 0,14 \\
Coage fisicamente & $1,17(1,15)$ & $1,28(0,96)$ & 0,78 \\
Pune fisicamente & $0,22(0,55)$ & $0,56(0,78)$ & 0,13 \\
\hline Não interferência & $1,56(1,38)$ & $1,67(1,03)$ & 0,87 \\
\hline Outras & $0,50(0,86)$ & $0,39(0,61)$ & 0,81 \\
\hline
\end{tabular}

Nota. Nivel de significância adotado: $p<0,05$.

TABELA 2

Média e Desvio-padrão das Práticas Educativas Paternas Relatadas aos 18 e 24 Meses de Idade da Criança $(n=18)$

\begin{tabular}{lccc}
\hline \multicolumn{4}{c}{ FAIXA ETÁRIA } \\
\hline Práticas educativas & 18 & 24 & $P$ \\
\hline Práticas Indutivas & $3,72(2,32)$ & $3,50(1,34)$ & 0,70 \\
Negocia e troca & $1,78(1,30)$ & $1,68(0,91)$ & 0,98 \\
Explica & $1,22(1,77)$ & $1,27(0,96)$ & 0,81 \\
Organiza ambiente & $0,33(0,48)$ & $0,17(0,38)$ & 0,25 \\
Comanda verbalmente sem coerção & $0,39(0,61)$ & $0,50(0,71)$ & 0,79 \\
\hline Práticas coercitivas & $2,83(2,50)$ & $2,06(1,51)$ & 0,25 \\
Pune verbalmente & $1,06(1,35)$ & $0,67(0,68)$ & 0,31 \\
Ameaça & $0,33(0,68)$ & $0,28(0,47)$ & 0,63 \\
Coage fisicamente & $1,17(1,04)$ & $0,89(0,90)$ & 0,45 \\
Pune fisicamente & $0,28(0,47)$ & $0,28(0,46)$ & 1,00 \\
\hline Não interferência & $1,61(1,24)$ & $2,06(1,76)$ & 0,59 \\
\hline Outras & $0,72(0,89)$ & $0,56(0,62)$ & 0,56 \\
\hline
\end{tabular}

Nota. Nivel de significância adotado: $p<0,05$.

O teste Wilcoxon também foi utilizado para comparar as práticas educativas maternas e paternas aos 24 meses de idade da criança, conforme o que já havia sido feito aos 18 meses (Piccinini \& cols., 2007). A Tabela 3 apresenta a incidência média, o desvio padrão e o nível de significância das práticas educativas maternas e paternas relatadas aos 24 meses de idade da criança. Os resultados revelaram que comparadas aos pais, as mães tiveram uma frequência significativamente maior de práticas classificadas nas subcategorias explica $(p<0,05)$ e organiza ambiente $(p<0,01)$, que integram a categoria práticas indutivas, que apa- 
receu com uma tendência na mesma direção, embora não significativa $(\mathrm{p}>0,09)$. As mães apresentaram ainda uma frequência significativamente maior de práticas coercitivas $(\mathrm{p}<0,03)$ do que os pais, com destaque para a sub-categoria ameaça com uma tendência não significativa $(\mathrm{P}<0,09)$.

TABELA 3

Média e Desvio-padrão das Práticas Educativas Maternas e Paternas Relatadas aos 24 Meses de Idade da Criança $(\mathrm{n}=18)$

\begin{tabular}{lccc}
\hline & \multicolumn{2}{c}{ FAIXA ETÁRIA } & \\
\hline Práticas educativas & Maternas & Paternas & $P$ \\
\hline Práticas Indutivas & $4,67(2,20)$ & $3,50(1,34)$ & 0,09 \\
Negocia e troca & $1,67(1,14)$ & $1,68(0,91)$ & 0,87 \\
Explica & $2,17(1,54)$ & $1,27(0,96)$ & 0,05 \\
Organiza ambiente & $0,56(0,51)$ & $0,17(0,38)$ & 0,01 \\
Comanda verbalmente sem coerção & $0,22(0,43)$ & $0,50(0,71)$ & 0,10 \\
\hline Práticas coercitivas & $3,44(1,69)$ & $2,06(1,51)$ & 0,03 \\
Pune verbalmente & $1,05(0,72)$ & $0,67(0,68)$ & 0,17 \\
Ameaça & $0,67(0,77)$ & $0,28(0,47)$ & 0,09 \\
Coage fisicamente & $1,28(0,96)$ & $0,89(0,90)$ & 0,12 \\
Pune fisicamente & $0,56(0,78)$ & $0,28(0,46)$ & 0,22 \\
\hline Não interferência & $1,67(1,03)$ & $2,06(1,76)$ & 0,48 \\
\hline Outras & $0,39(0,61)$ & $0,56(0,62)$ & 0,44 \\
\hline
\end{tabular}

Nota. Nível de significância adotado: $p<0,05$.

\section{DISCUSSÃO}

O presente estudo buscou investigar a estabilidade e as mudanças nas práticas educativas de pais e mães dos 18 para os 24 meses de vida de suas crianças. Além disso, foram comparadas as práticas educativas maternas e paternas aos 24 meses. A hipótese inicial era de que aos 24 meses pais e mães relatariam mais práticas indutivas do que aos 18 meses, devido à crescente aquisição de autonomia e assertividade nas crianças e ao desenvolvimento da linguagem. Esta hipótese foi parcialmente apoiada pelos resultados, pois apenas as mães relataram mais práticas indutivas aos 24 meses do que aos 18 meses de vida dos filhos. O crescente domínio da linguagem (Mussen \& cols., 1990), o surgimento da assertividade (Crockenberg \& Litman, 1990; Kuczynski e cols., 1987) e a maior atribuição de competência e responsabilidade à criança (Dix \& cols., 1989) são fatores relevantes para a compreensão desta diferença. Diante de uma recusa assertiva da criança, por exemplo, é natural que os pais lancem mão de mais estratégias verbais para regular seu comportamento.

Por outro lado, chama atenção que isto não tenha ocorrido também com os pais. Esta diferença entre pais e mães pode ser explicada pelo fato de que, por estarem mais envolvidas nos cuidados com os filhos nesta etapa do desenvolvimento (Belsky, 1979), as mães estariam mais suscetíveis às mudanças típicas nas habilidades da criança. Por se ocuparem com maior frequência do que os pais de tarefas cotidianas que geram conflitos (Booth \& cols., 1992), tais como aquelas que foram investigadas no presente estudo, as mães acabariam desenvolvendo um repertório mais amplo de estratégias indutivas, como o uso de explicações, por exemplo, para lidar com essas situações. Além disso, alguns estudos indicam que as mães tendem a utilizar mais a linguagem ao lidar com a criança, quando comparadas aos pais (Parke, 1981; Schaffer, 1996). Deste modo, o desenvolvimento da assertividade e da linguagem na criança operaria de modo mais frequente e intenso sobre as práticas maternas do que sobre as práticas paternas, pelo menos em parte, devido ao fato de as mães serem expostas a essas novas habilidades infantis com mais frequência.

Uma segunda hipótese foi de que não haveria diferenças nas práticas educativas maternas e paternas aos 24 meses da criança, considerando os achados do estudo de Piccinini e cols. (2007), que incluiu a amostra 
de famílias do presente estudo e não encontrou diferenças entre as práticas educativas dos pais e das mães. Contudo, os resultados do presente estudo não apoiaram a hipótese, pois as mães apresentaram uma frequência significativamente maior do que os pais de práticas envolvendo explicação e organização do ambiente. Além disso, elas também relataram mais práticas coercitivas do que os pais aos 24 meses da criança. Esses achados reforçam o argumento de maior envolvimento das mães nos cuidados com a criança, inclusive quando são necessárias verbalizações e ações que visam restringir certos comportamentos.

Isto pode também estar indicando as dificuldades enfrentadas pelas mães ao lidarem com as mudanças no repertório de comportamentos da criança, tendo em vista a aquisição de novas habilidades, o que se refletiria na maior frequência de práticas coercitivas. $\mathrm{O}$ estudo de Lopes e cols. (2007) revelou que diante das novas aquisições da criança em torno dos 12 meses, as mães manifestaram sentimentos positivos, relacionados ao crescimento e desenvolvimento dos filhos, mas também relataram sentimentos negativos como cansaço e estresse relacionados à maior demanda e dedicação. A ausência de diferenças no estudo realizado aos 18 meses, que incluiu a amostra do presente estudo (Piccinini \& cols., 2007), pode ser explicada pelo fato de que, naquele momento, as novas habilidades ligadas à linguagem, ainda encontravam-se em um estágio inicial, enquanto que, no vigésimo quarto mês de vida, estariam mais estabelecidas.

Contudo, é importante salientar que a literatura revisada não aponta para diferenças significativas nas práticas de pais e mães (Bentley \& Fox, 1991; Chao \& Kim, 2000; Piccinini \& cols., 2007), com exceção dos estudos que avaliaram amostras de pais de crianças com dificuldades comportamentais (Arnold \& O'Leary, 1997; Baker \& Heller, 1996), aspecto não avaliado no presente estudo. As diferenças encontradas no presente estudo parecem estar relacionadas ao período específico que foi avaliado, caracterizado por mudanças marcantes no comportamento infantil, que tendem a se refletir também em mudanças no repertório comportamental dos pais. Nesse sentido, a parentalidade se constitui em um processo de acomodação mútua entre pais e filhos, na busca de um equilíbrio entre o controle por parte dos pais e a autonomia dos filhos (Minuchin, 1982).

Como já foi salientado anteriormente os achados da literatura sobre a estabilidade e as mudanças nas práticas educativas parentais ao longo do desenvolvi- mento infantil são controversos. Essas inconsistências se justificam, em parte, por diferenças conceituais e metodológicas. Nesse sentido, enquanto estudos que avaliam práticas parentais ou estratégias disciplinares indicariam tendência à mudança ao longo do desenvolvimento, os estudos que adotam conceitos e medidas relacionados a atitudes e estilos parentais apontariam para a estabilidade. Somado a estas questões metodológicas, o curto período de desenvolvimento infantil que foi considerado no presente estudo e que envolve aquisições de novas habilidades pode explicar as mudanças encontradas no uso das práticas educativas. De qualquer modo, é interessante retomar os resultados de Dallaire e Weinraub (2005), que apontaram a estabilidade de diversos comportamentos maternos e paternos tais como sensibilidade, presença apoiadora, e também os de desapego e atenção negativa entre o $15^{\circ}$ e o $24^{\circ}$ mês de vida da criança, variáveis essas não investigadas no presente estudo. Contudo, é possível notar que as categorias analisadas pelas autoras referem-se, predominantemente, a atitudes parentais mais globais, e não a estratégias de regulação do comportamento infantil em situações específicas e cotidianas, potencialmente de conflito, como as que foram avaliadas no presente estudo.

Os resultados obtidos indicam a relevância do estudo da estabilidade e das mudanças nas práticas educativas parentais e a necessidade de novas pesquisas que aprofundem esta temática. É importante que sejam ainda investigados outros momentos críticos do desenvolvimento infantil, bem como os fatores que explicam tais mudanças no repertório parental. Outra questão suscitada pelos resultados diz respeito ao nível de envolvimento materno e paterno em diferentes atividades e situações cotidianas com os filhos nesta etapa do desenvolvimento. Uma das hipóteses explicativas adotadas na interpretação dos resultados foi a de maior envolvimento materno em todas as situações inclusive as de conflito com as crianças. Novos estudos podem investigar, por exemplo, como o casal lida com essas diferenças na educação de seus filhos, pois é importante que pais e mães se apoiem em seus papéis parentais (Frizzo, Kreutz, Schmidt, Bosa \& Piccinini, 2005), mesmo quando assumem diferentes funções na socialização da criança. Estes conhecimentos poderão auxiliar na identificação das etapas do desenvolvimento infantil em que os pais tendem a necessitar de mais apoio e orientação para lidar com as novas aquisições infantis, particularmente a autonomia dos filhos. 


\section{REFERÊNCIAS}

Alvarenga, P., \& Piccinini, C. (2003). Práticas educativas maternas e a interação entre mães e crianças com problemas de externalização. Aletheia, 17/18, 7-20.

Alvarenga, P., \& Piccinini, C. A. (2001). Práticas educativas maternas e problemas de comportamento em pré-escolares. Psicologia: Reflexão e Crítica, 14(3), 449-459.

Arnold, E., H., \& O'Leary, S. G. (1997). Mothers and fathers discipline of hard-to-manage toddlers. Child and Family Behavior Therapy, 19(3), 1-11.

Baker, B. L., \& Heller, T. L. (1996). Preschool children with externalizing behaviors: Experience of fathers and mothers. Journal of Abnormal Child Psychology, 24(4), 513-532.

Bardin, L. (1977). Análise de conteúdo. Lisboa: Edições 70.

Baumrind, D. (1972). An exploratory study of socialization effects on black children: Some black-white comparisions. Child Development, 43, 261-267.

Belsky, J. (1979). Mother-father-infant interaction: A naturalistic observational study. Developmental Psychology, 15(6), 601607.

Bentley, K. S., \& Fox, R. A. (1991). Mothers and fathers of young children: Comparision of parenting styles. Psychological Reports, 69, 320-322.

Booth, C. L., Spieker, S. J., Barnard, K. E., \& Morisset, C. E. (1992). Infants at risk: The role of preventive intervention in deflecting a maladaptative developmental trajectory. Em J. McCord, \& R. E. Tremblay (Orgs.), Preventing antisocial behavior: Interventions from birth through adolescence (pp. 2142). New York/London: Guilford Press.

Chao, R. K., \& Kim, K. (2000). Parenting differences among immigrant chinese fathers and mothers in the United States. Journal of Psychology in Chinese Societies, 1(1) 71-91.

Crockenberg, S. B., \& Litman, C. (1990). Autonomy as competence in 2-year-olds: Maternal correlates of child defiance, compliance and self-assertion. Developmental Psychology, 26(6), 961-971.

Dallaire, D. H., \& Weinraub, M. (2005). The stability of parenting behaviors over the first 6 years of life. Early Childhood Research Quarterly, 20, 201-219.

Darling, N., \& Steinberg, L. (1993). Parenting style as context: An integrative model. Psychological Bulletin, 113, 487-496.

Dix, T., Ruble, D. N., \& Zambarano, R. J. (1989). Mother's implicit theories of discipline: Child effects, parent effects, and the attribution process. Child Development, 60, 1373-1391.

Frizzo, G. B., Kreutz, C. M., Schmidt, C., Piccinini, C. A., \& Bosa, C. A. (2005). O conceito de coparentalidade e suas implicações para a pesquisa e para a clínica. Revista Brasileira de Crescimento e Desenvolvimento Humano, 15(3), 84-94.

GIDEP - Grupo de Interação Social, Desenvolvimento e Psicopatologia (1998). Entrevista de dados demográficos Instrumento não-publicado, Instituto de Psicologia, Universidade Federal do Rio Grande do Sul.

Grusec, J. E., \& Lytton, H. (1988). Social development: History, theory and research. New York: Springer-Verlag.
Hart, C. H., Ladd, G. W., \& Burleson, B. R. (1990). Expectations of the outcomes of social strategies: Relations with socioeconomic status and maternal disciplinary styles. Child Development, 61, 127-137.

Hoffman, M. L. (1975). Moral internalization, parental power, and the nature of parent-child interaction. Developmental Psychology, 11, 228-239.

Hoffman, M. L. (1979). Development of moral thought, feeling, and behavior. American Psychologist, 34, 958-966.

Hoffman, M. L. (1994). Discipline and internalization. Developmental Psychology, 30, 26-28.

Kuczynski, L., Kochanska, G., Radke-Yarrow, M., \& GirniusBrown, O. (1987). A developmental interpretation of young children's noncompliance. Developmental Psychology, 23, 799-806.

Landry, S. H., Smith, K. E., Swank, P. R., Assel, M. A., \& Vellet, S. (2001). Does early responsive parenting have a special importance for children's development or is consistency across early childhood necessary? Development Psychology, 37(3), 387-403.

Lopes, R. C. S., Oliveira, D. S., Vivian, A. G., Bohmgahren, L. M. C., Piccinini, C. A., \& Tudge, J. (2007). Sentimentos maternos frente ao desenvolvimento da criança aos 12 meses: Convivendo com as novas aquisições infantis. Psicologia: Teoria e Pesquisa, 23(1), 5-15.

McNally, S., Eisenberg, N., \& Harris, J. D. (1991). Consistency and change in maternal child-rearing practices and values: A longitudinal study. Child Development, 62, 190-198.

Minuchin, S. (1982). Famílias: Funcionamento e tratamento (J. A. Cunha, Trad.). Porto Alegre: Artes Médicas. (Original publicado em 1974)

Mussen, P. H., Conger, J. J., Kagan, J., \& Huston, A. C. (1990). Child Development \& Personality. New York: Harper \& Row.

Papalia, D. E., \& Olds, S. W. (2000). Desenvolvimento humano (D. Bueno, Trad.). Porto Alegre: Artmed.

Parke, R. D. (1981). Fathering. London: Collins.

Piccinini, C. A, \& Alvarenga, P. (2001). Entrevista sobre Práticas Educativas Parentais. Instrumento não-publicado, Instituto de Psicologia, Universidade Federal do Rio Grande do Sul.

Piccinini, C. A, Castro, E. K., Alvarenga, P., Vargas, S., \& Oliveira, V. Z. (2003). A doença crônica na infância e as práticas educativas maternas. Estudos de Psicologia, 8(1), 75-83.

Piccinini, C. A., Frizzo, G. B., Alvarenga, P., Lopes, R. S., \& Tudge, J. (2007). Práticas educativas de pais e mães de crianças aos 18 meses de idade. Psicologia: Teoria e Pesquisa, 23, 369-378.

Piccinini, C. A., Lopes, R. C. S., Sperb, T. M., \& Tudge, J. R. H. (1998). Estudo longitudinal de Porto Alegre. Projeto de pesquisa não-publicado, Universidade Federal do Rio Grande do Sul.

Roberts, G. C., Block, J. H., \& Block, J. (1984). Continuity and change in parent's child-rearing practices. Child Development, $55,586-597$.

Robson, C. (1995). Real world research. Oxford: Blackwell.

Schaffer, H. R. (1996). Social development. Oxford: Blackwell. 
Tudge, J. R. H., \& Frizzo, G. F. (2002). Classificação baseada em Hollingshead do nível sócio-econômico das famílias do estudo longitudinal de Porto Alegre: Da gestação à escola. Manuscrito não-publicado, Universidade Federal do Rio Grande do Sul.

Recebido: 29/10/2008

Última revisão: 10/07/2009

Aceite final: 29/09/2009

\section{Sobre os autores:}

Patrícia Alvarenga: Doutora em Psicologia do Desenvolvimento (Universidade Federal do Rio Grande do Sul). Professora do Programa de Pós-Graduação de Psicologia da Universidade Federal da Bahia.

Cesar Augusto Piccinini: Doutor pela University College London (Inglaterra). Pesquisador do CNPq e Professor do Curso de Pós-Graduação em Psicologia do Desenvolvimento da Universidade Federal do Rio Grande do Sul.

Giana Bitencourt Frizzo: Doutora em Psicologia do Desenvolvimento (Universidade Federal do Rio Grande do Sul). Professora do Departamento de Psicologia do Desenvolvimento e Personalidade da Universidade Federal do Rio Grande do Sul.

Rita Sobreira Lopes: Doutora pela University College London (Inglaterra). Professora do Curso de Pós-Graduação em Psicologia do Desenvolvimento da Universidade Federal do Rio Grande do Sul.

Jonathan Tudge: Doutor pela Cornell University (EUA). Professor Titular em Desenvolvimento Humano e Estudo da Família da University of North Carolina at Greensboro (EUA).

Endereço para correspondência: Instituto de Psicologia - Universidade Federal do Rio Grande do Sul - Rua Ramiro Barcelos, 2600 sala 111 - 90035-003 Porto Alegre - RS. - Endereço eletrônico: piccinini@portoweb.com.br. 